\title{
Independent of body adiposity, breast-feeding has a protective effect on glucose metabolism in young adult women
}

\author{
Juliana M. M. Diniz ${ }^{1}$ and Teresa H. M. Da Costa ${ }^{2 *}$ \\ ${ }^{1}$ Graduate Course, Department of Nutrition, Universidade de Brasilia, Brasilia, Brazil \\ ${ }^{2}$ Department of Nutrition, Faculty of Health Sciences, Universidade de Brasilia, Brasilia, C.P. 04511, CEP 70919-970, \\ Brazil
}

(Received 1 December 2003 - Revised 30 June 2004 - Accepted 16 August 2004)

\begin{abstract}
The objective of the present study was to determine if any associations between reproductive experience and anthropometric or sub-clinical metabolic alterations of glucose metabolism exist. Sixty-seven women were recruited from the University of Brasilia Hospital and were evaluated at 12-18 months postpartum. Demographic, socio-economic, physical activity, anthropometric and health history (biochemical, reproductive) data were obtained. After a $12 \mathrm{~h}$ overnight fast, a $2 \mathrm{~h}$ oral glucose tolerance test was performed. Blood samples were collected at several points: at baseline, after intake of D-glucose solution $(750 \mathrm{~g} / \mathrm{l} ; 100 \mathrm{ml})$ and every $30 \mathrm{~min}$ thereafter. Blood glucose and lipids were measured by enzymic assays. Blood insulin was measured by RIA. In multiple regression analysis four dependent logarithmically transformed (logt) variables (increased area under the glucose curve (IAUGC), increased area under the insulin curve (IAUIC), insulin peak (IP), homeostasis model of assessment (HOMA)) were adjusted for parity, age, lactation index, BMI, percentage body fat (PBF), waist circumference, superior skinfold thickness sum:inferior skinfold thickness sum ratio and oral contraceptive use. PBF was positively associated with logt-IAUIC $(P=0.004)$ and IP $(P=0.006)$. However, the lactation index was negatively associated with logt-IAUIC $(P=0.02)$. IAUGC and HOMA did not present significant associations. We conclude that during the postnatal period, independent of parity, body adiposity accumulation is associated with initial alterations in insulin secretion. Furthermore, independent of body adiposity, breast-feeding has a long-lasting protective effect on insulin response.
\end{abstract}

\section{Adiposity: Lactation: Glucose metabolism}

Excessive body weight is an important health problem that is increasing in prevalence worldwide (World Health Organization, 1997; Khan \& Bowman, 1999). In Brazil, overall prevalence of obesity $\left(\mathrm{BMI} \geq 30 \cdot 0 \mathrm{~kg} / \mathrm{m}^{2}\right.$ ) increased from 5.7 to $9.6 \%$ from 1974 to 1989 . Lower income women had the greatest prevalence of obesity (30\%; Monteiro et al. 1995). This trend continued from 1989 to 1997, with a prevalence of $27 \%$ among north-eastern women and poor south-eastern women (Monteiro et al. 2000).

According to WHO, pregnancy is a critical period for weight gain and obesity in women (World Health Organization, 1997). Not only does weight gain occur, but the pattern of body adiposity changes after pregnancy. Positive associations have been found between parity and waist:hip ratio (Smith et al. 1994; Ness, 1995; Soltani \& Fraser, 2000; Rodrigues \& Da Costa, 2001) and between parity and percentage body fat (PBF; Rodrigues \& Da Costa, 2001). Moreover, Soltani \& Fraser (2000) observed that anthropometric pattern changes postpartum had greater variability among pre-gestational obese women (as classified by The Institute of Medicine, 1990) compared with normal and overweight $\left(\mathrm{BMI} \geq 25 \cdot 0 \mathrm{~kg} / \mathrm{m}^{2}\right.$ ) women. In addition, pre-pregnancy obesity may play an important role in weight gain during the gestational period. Finally, due to biological and psychological factors that accompany motherhood, changes in dietary behaviour occur. In turn, these dietary changes strongly influence adiposity retention (Brewer et al. 1989; Piers et al. 1993; Harris et al. 1999; Butte et al. 2001).

Zhong et al. (1990) performed intravenous glucose tolerance tests (GTT) during the third gestational period in three different groups of rats: control virgin group; two pregnancies and no lactation group; two pregnancies plus lactation group. The two pregnancies and no lactation group had a greater fasting glucose concentration than the two pregnancies plus lactation group. The sum of total insulin concentrations of the two pregnancies and no lactation group throughout the intravenous GTT was generally greater than that of the two pregnancies plus lactation group. In the two pregnancies and no lactation group, a glucose intolerant state was diagnosed. The two pregnancies and no lactation group had increased body subcutaneous fat, but no change in total body weight. In contrast, the two pregnancies plus lactation group had prolonged body weight elevation and increased fat pad weight.

Abbreviations: GTT, glucose tolerance test; HOMA, homeostasis model of assessment; HPBF, high percentage body fat; HW, heavy weight; IAUGC, increased area under the glucose curve; IAUIC, increased area under the insulin curve; IP, insulin peak; ISS, inferior skinfold thickness sum; logt, log-transformed; NPBF, normal percentage body fat; NW, normal weight; PBF, percentage body fat; SSS, superior skinfold thickness sum.

* Corresponding author: Dr Teresa H. M. Da Costa, fax +55 61347 9746, email hdacosta@unb.br 
In human subjects, physiological insulin resistance, which may represent an evolutional advantage for women, has been observed in the last trimester of gestation. A plausible biological explanation could be increased glucose utilization by placental-fetal tissues (Catalano et al. 1998; Butte et al. 1999; Sivan et al. 1999). Insulin resistance could also increase insulin bioavailability for mammary tissue. This is consistent with research on human subjects (Neville et al. 1991) and rats (Da Costa \& Williamson, 1994) that show that mammary lipoprotein lipase is also regulated by insulin. However, there is little known about this physiological insulin resistance period and its long-term effect on metabolism.

Taking into consideration the physiological alterations that occur during pregnancy and lactation, we hypothesized that multiparity could be a risk factor for sub-clinical abnormalities in glucose metabolism. The aim of the present study was to discover if there are sub-clinical alterations of glucose metabolism in young adult women and if there are any associations with parity, adiposity and lactation. To this end, we developed an observational, prospective and cross-sectional study using a protocol established in our laboratory (Rodrigues \& Da Costa, 2001).

\section{Material and methods}

\section{Recruitment}

Volunteers were contacted when bringing their infant for routine examination at an outpatient clinic at the University of Brasilia Hospital (Brazil). Women who fulfilled the following inclusion factors were selected: 12-18 months postpartum; 18-42 years of age; one or more complete gestational cycles. We ensured that the primiparous and multiparous groups were matched according to the inclusion criteria. Women were not chosen if any of the following exclusion factors were present: twin births; pre-term ( $<38$ weeks) birth in the last gestation; first complete gestational cycle at $<18$ years of age; use of drugs that could interfere with glucose or lipid metabolism (except oral contraceptives); health problems such as diabetes mellitus, hypertension, cancer, endocrine dysfunction, polycystic ovary syndrome, irregular menstrual cycles; receiving treatment for obesity; broad fluctuations in food intake. After the study objectives and methods were explained, volunteers signed an informed consent term approved by the Faculty of Health Sciences Ethical Committee of the University of Brasilia.

\section{Demographic and socio-economic data}

Identification, hospital registration number, date of birth, address, telephone number, marital status (single, married, divorced), ethnicity (predominantly black or white), educational level (years of complete schooling), profession and occupational information were obtained. Information on family income (five levels based on multiples of the Brazilian minimum wage: $1,1-2,3-5,6-10$ and $>10$ ) and on the number of children and adults living in the household was also collected.

We classified women into low or high socio-economic status. Women were considered to be of low socio-economic status if they fulfilled at least two of the following criteria: absent or incomplete secondary education; income less than ten times the Brazilian minimum wage; no refrigerator and/or freezer. High socio-economic women fulfilled at least two of the following criteria: completed secondary education; income more than ten times the minimum Brazilian wage; possession of refrigerator and/or freezer.

\section{Health and reproductive data}

A questionnaire that had previously been established in our laboratory was used (Rodrigues \& Da Costa, 2001). In addition, two questions were added to gather information on: (1) time of exclusive breast-feeding (human milk only, with no intake of water and/or teas); (2) any noticeable change in body weight or shape after pregnancy. Women who experienced only one gestational cycle were classified as primiparous and those who presented two or more were classified as multiparous. Information on current use of medication, oral contraceptive and cigarette smoking was collected. Physical activity was classified into four levels based on exercise and occupational activities: (1) sedentary; (2) $<4 \mathrm{~h}$ regular physical exercise per week; (3) $>4 \mathrm{~h}$ regular physical exercise per week; (4) heavy physical activity and/or participation in competitive sports.

\section{Anthropometry}

The methods for anthropometric measurements have been described in detail by Rodrigues \& Da Costa (2001). Briefly, body weight and height were measured in all women. PBF was estimated by using Siri's equation (1961). The equations of Durnin \& Womersley (1974) were used to estimate body density. Skinfold thickness measurements were performed on the right side of the body at the following sites: triceps, subscapular, suprailiac, thigh. Two measurements were taken to the nearest $0.2 \mathrm{~mm}$ using a Harpender calliper (CMS Weighing Equipment, London, UK) and the average of the readings recorded. A third reading was taken if a difference of $>1.0 \mathrm{~mm}$ was obtained. In this case, the average of the two closest readings was recorded. In the present study, only one author (T. H. M. C.) was responsible for these measurements. Pre-pregnant weight information as recalled by the volunteers was also recorded. Using a method adapted from Ness (1995), we calculated superior skinfold thickness sum (triciptal + subscapular; SSS):inferior skinfold thickness sum (suprailiac + thigh; ISS) ratio.

\section{Oral glucose tolerance test}

An oral GTT was carried out during the follicular phase of the menstrual cycle (between days 14 and 16). After a 10-12 h overnight fast, blood pressure was taken and an antecubital vain was punctured and kept patent with heparin solution (Liquemine ${ }^{\circledR}$; Produtos Roche Quinicos e Farmacêuticos S.A., Rio de Janeiro, Brazil; 1:10 dilution in $\mathrm{NaCl}$ solution $(9 \mathrm{~g} / \mathrm{l})$ ). Blood samples were collected at baseline $(0 \mathrm{~min})$. The subjects then consumed $100 \mathrm{ml}$ D-glucose $\left(750 \mathrm{~g} / \mathrm{l} ;\right.$ Dextrosol $^{\circledR}$; Refinações de milho 
LTDA, Pouso Alegre MG, Brazil). Ingestion of the glucose solution was monitored so that it took 5-10 min. Water was then added to the cup that contained the sugar solution and this diluted mixture was ingested by the women. This was repeated to ensure that the all of the glucose was consumed. Blood was then collected every $30 \mathrm{~min}$ for the next $2 \mathrm{~h}$. Blood samples were collected in vacuum tubes (Vacutainer $^{\circledR}$; Becton Dickinson and Company, Franklin Lakes NJ, USA) for serum and in heparinized vacuum tubes (Vacutainer ${ }^{\circledR}$ ) for plasma. Samples were kept on ice before centrifugation (Clay Adams ${ }^{\circledR}-0101$, DYNAC, EUA; $3500 \mathrm{rpm}$ for $5 \mathrm{~min}$ ). Serum and plasma were harvested and stored at $-18^{\circ} \mathrm{C}$ until analysis.

\section{Laboratory analyses}

Glucose (0, 30, 60, 90 and $120 \mathrm{~min})$, fasting total cholesterol and triacylglycerol concentration determinations were conducted on plasma. Fasting HDL-cholesterol was measured in serum. All measurements were done using enzymic methods according to the manufacturer's recommendations (Labtest ${ }^{\circledR}$; Labtest Diagnostica S.A., Belo Horizonte, Brazil). Serum insulin concentrations $(0$, 30, 60, 90, and $120 \mathrm{~min}$ ) were determined by RIA $\left(\right.$ DPC $^{\circledR}$, Diagnostic Products Corporation, Los Angeles, CA, USA; $24 \mathrm{~h}$ incubation period).

For estimates of VLDL-cholesterol, the equation VLDL-cholesterol $=$ triacylglycerol/5 was used. For LDLcholesterol, the equation LDL-cholesterol $=$ total cholesterol - (HDL-cholesterol + VLDL-cholesterol) was used (Friedewald et al. 1972). The CV obtained during biochemical analyses were 3-10\%, all within the manufacturers' acceptable ranges.

\section{Calculations}

The lactation index was calculated by the method of Rodrigues \& Da Costa (2001). In brief, a scoring system was used in which points were assigned based on the number of months of breast-feeding per child: $<1$ month, 0 points; 1-5 months, 2 points per month; 6 months, 3 points per month; 7-9 months, 4 points per month; $9-11$ months, 5 points per month; $\geq 12$ months, 6 points per month. A range of $0-72$ points could be obtained by each mother per child. This lactation index accounts for the establishment and maintenance of the physiological process of lactation over time. The mean lactation index was calculated by dividing the total number of points by the number of children. Sixty percent of the women were still breast-feeding (forty of sixty-seven) at the time of sample collection. When classified by PBF, the proportion of breast-feeding women was similar (for PBF $<25$ eleven out of eighteen $(61 \%)$, for $\mathrm{PBF} \geq 25$ twenty-nine out of forty-nine $(59 \%) ; P=0.88)$.

Increased areas under the curve for glucose (IAUGC) and insulin (IAUIC) were calculated by subtracting basal area under the curve from total area under the curve for each variable. To calculate total area under the curve, the formula for calculating the area of trapezoids was used (Matthews et al. 1990). For basal area under the curve, the formula for calculating the area of rectangles was used (basal value $\times 120 \mathrm{~min}$ ).
Glucose peak and insulin peak (IP) were defined as the highest concentrations during the oral GTT. Insulin sensitivity was measured by the homeostasis model of assessment (HOMA) as described by Matthews et al. (1985) by taking the product of fasting plasma glucose and fasting insulin and dividing it by 22.5. It was assumed that normal young subjects have an insulin resistance of 1 (Kirwan et al. 2001).

\section{Statistical analyses}

Data from excluded and included volunteers were compared by Student's $t$ test to verify the absence of systematic exclusion. Comparisons between mean values (with standard deviations) for primiparous and multiparous women were done by Student's $t$ test or CI $(95 \%)$. The $\chi^{2}$ test was used to compare categorical variables. Control of type I error resulting from multiple comparisons was obtained by dividing the $\alpha$ level by the number of comparisons (Dawson-Saunders \& Trapp, 1994). The level of significance used was $5 \%$.

Multivariable analysis (using SAS version 6.0 for Windows 98; SAS Institute Inc., Cary, NC, USA) was also performed. Multiple regression analysis was used for continuous variables such as: log-transformed (logt) IAUGC, IAUIC, IP and HOMA index (response variables). The models were adjusted by parity, age, lactation index, PBF, actual BMI, waist circumference, SSS:ISS ratio and oral contraceptive use (explanatory variables). Because response variables presented right asymmetric normal distributions, we used their logt values in multiple regression analysis.

Dietary data were obtained from $24 \mathrm{~h}$ recall and food-frequency questionnaires, but they were not included in multivariable analysis. This is because food intake was under-reported more often by obese women than by lean women. The prevalence of under-reporting in the $24 \mathrm{~h}$ recall questionnaire was measured as food intake level (Goldberg et al. 1991). Prevalence of food intake level $<1.2$ was $34 \%$ for lean women $v .95 \%$ for overweight women $(P<0.0001)$.

A multi-collinear relationship between waist:hip ratio and waist circumference was observed. Thus, waist:hip ratio was not included in any multivariable analysis. Prepregnant BMI was not included in multivariable analysis due to the fact that $22.4 \%$ of this data was incomplete.

\section{Results}

Eleven women were excluded out of seventy-eight, resulting in a $14 \%$ loss. Reasons for exclusion were diagnosis of diabetes after the oral GTT, start of dietary treatment for obesity just before analysis, clinical symptoms during the oral GTT such as vomiting, and inadequate handling of samples. There were no statistical differences between the excluded group and the study groups, indicating that the exclusions were not systematic (results not shown). Study groups were composed of equal percentages of ethnicities $(50 \%$ predominantly black and $50 \%$ predominantly white). Most women were in the lower socio-economic level $(75 \%)$, lived in satellite cities outside of 
Brasilia (89\%), and were married (89\%), sedentary (89\%) and non-smokers $(88 \%)$.

\section{Primiparous v. multiparous}

Demographic, socio-economic, health history, reproductive history, physical activity, dietary, anthropometric and clinical data from primiparous and multiparous subjects were compared (Table 1). There were no differences between these two groups.

\section{Anthropometric and biochemical results}

Anthropometric results are presented in Table 1. Primiparous and multiparous women had normal BMI levels according to the World Health Organization (1997) classification. They were 22.6 (95\% CI 20.8, 24.4) and 24.2 $(95 \%$ CI $22.5,25.9) \mathrm{kg} / \mathrm{m}^{2}$ respectively. PBF levels observed were 27.3 (95\% CI 24.3, 30.4) for primiparous and 29.9 (95\% CI 27.6, 32.2) for multiparous women.

Due to the characteristics of the present study, a small sample of volunteers was examined. Variables that did not show any statistical difference between primiparous and multiparous groups, such as physical activity level, socio-economic status and smoking, were excluded from regression model analysis (Table 1). However, oral contraceptive usage was included because of its association with decreased glucose tolerance, a potential confounder of the analysis. Oral contraceptive use in primiparous women was $47 \%$ ( $n$ 14) and among multiparous women $41 \%$ ( $n$ 15).
Table 2 presents multiple regression analysis data. The model included four dependent logt variables: IAUGC, HOMA, IAUIC and IP. IAUGC and HOMA had non-significant model $F$ values of $1.52(P=0.17)$ and 1.48 $(P=0.18)$ respectively. As a consequence, none of the independent variables tested showed any significant associations. Parity was not associated with insulin responses (logt-IAUIC $P=0.35$; logt-IP $P=0 \cdot 60$ ) during the oral GTT. However, lactation was inversely related to total insulin response (lactation index and logt-IAUIC $F$ $-2.51, P=0.02)$ and also to IP (lactation index and logtIP $F-1.70, P=0.09$ ). This indicates that women who have breast-fed for long periods tend to be more sensitive to insulin and therefore need less insulin to dispose of orally consumed glucose. PBF was the only anthropometric variable that showed a positive association with insulin response (logt-IAUIC $F$ 3.054, $P=0.004$; IP $F$ 2.87, $P=0 \cdot 006)$.

After determination of PBF as the best predictor of insulin response and lactation index as a protective factor, the study group was divided into four groups according to PBF $(<25$ and $\geq 25)$ and lactation index $(<50$ and $\geq 50)$. The mean value of lactation index for the total group was selected as the cut-off point. IAUGC, IAUIC, and glucose and insulin curves during the time period of the oral GTT for these four groups are presented in Fig. 1.

The glucose curves of all four groups are in the range considered 'normal' by the World Health Organization (1999). Insulin was positively associated with PBF and negatively associated with lactation index. Glucose

Table 1. Demographic, socio-economic, health and reproductive history, physical activity, dietary, anthropometric and clinical data from primiparous and multiparous women ${ }^{*} \dagger$

\begin{tabular}{|c|c|c|c|c|c|c|}
\hline & \multicolumn{2}{|c|}{$\begin{array}{l}\text { Primiparous } \\
(n 30 ; 45 \%)\end{array}$} & \multicolumn{2}{|c|}{$\begin{array}{l}\text { Multiparous } \\
(n 37 ; 55 \%)\end{array}$} & \multirow[b]{2}{*}{ df } & \multirow{2}{*}{$\begin{array}{l}\text { Statistical significance of } \\
\text { effect }\left(\chi^{2} \text { test): } P\right.\end{array}$} \\
\hline & $n$ & $\%$ & $n$ & $\%$ & & \\
\hline \multicolumn{7}{|l|}{ Socio-economic status } \\
\hline High & 9 & 30 & 8 & 22 & 1 & 0.43 \\
\hline Low & 21 & 70 & 29 & 78 & & \\
\hline \multicolumn{7}{|l|}{ Ethnicity } \\
\hline Predominantly black & 11 & 39 & 21 & 58 & 1 & 0.13 \\
\hline Predominantly white & 17 & 61 & 15 & 42 & & \\
\hline \multicolumn{7}{|l|}{ Marital status } \\
\hline Single & 2 & 7 & 3 & 8 & 2 & 0.95 \\
\hline Married & 27 & 90 & 32 & 89 & & \\
\hline Divorced or widow & 1 & 3 & 1 & 3 & & \\
\hline \multicolumn{7}{|l|}{ Physical activity } \\
\hline Sedentary $(<4 \mathrm{~h}$ per week) & 25 & 93 & 35 & 100 & 1 & 0.10 \\
\hline Active ( $\geq 4 \mathrm{~h}$ per week) & 2 & 7 & 0 & 0 & & \\
\hline \multicolumn{7}{|l|}{ Smoking } \\
\hline Non smoker & 25 & 83 & 34 & 92 & 1 & 0.28 \\
\hline Smoker & 5 & 17 & 3 & 8 & & \\
\hline Age at first pregnancy (years) & $24 \cdot 7$ & $22 \cdot 6,26 \cdot 8$ & $23 \cdot 1$ & $20 \cdot 8,25 \cdot 4$ & & \\
\hline Actual age (years) $\ddagger$ & $25 \cdot 8$ & $23 \cdot 7,27 \cdot 8$ & 29.9 & $27 \cdot 5,32 \cdot 5$ & & \\
\hline Lactation index $\ddagger$ & 55.9 & $42 \cdot 0,69 \cdot 9$ & $47 \cdot 2$ & $37 \cdot 2,57 \cdot 2$ & & \\
\hline Actual BMI $\left(\mathrm{kg} / \mathrm{m}^{2}\right) \ddagger$ & $22 \cdot 6$ & $20 \cdot 8,24.4$ & $24 \cdot 2$ & $22.5,25.9$ & & \\
\hline Body fat $(\%) \ddagger$ & $27 \cdot 3$ & $24 \cdot 3,30 \cdot 4$ & 29.9 & $27 \cdot 6,32 \cdot 2$ & & \\
\hline Waist circumference $(\mathrm{cm}) \ddagger$ & $75 \cdot 6$ & $71 \cdot 2,80 \cdot 0$ & 77.9 & $74 \cdot 0,81 \cdot 8$ & & \\
\hline Waist:hip ratioł & 0.79 & $0.77,0.82$ & 0.80 & $0.77,0.83$ & & \\
\hline SSS:ISS $\ddagger$ & 0.92 & $0.81,1.02$ & 0.92 & $0.84,1.01$ & & \\
\hline
\end{tabular}

SSS, superior skinfold thickness sum; ISS, inferior skinfold thickness sum.

${ }^{*}$ For details of subject selection and procedures, see pp. 906-907.

† Information on ethnicity, marital status, physical activity and SSS:ISS in some women could not be completed.

$\ddagger$ Mean values and $95 \% \mathrm{Cl}$. 
Table 2. Multiple regression analysis for log-transformed (logt) increased area under the insulin curve (logt-IAUIC) and insulin peak $(\log -\mathrm{IP})^{\star}$

\begin{tabular}{lccccc}
\hline & \multicolumn{2}{c}{ Logt-IAUIC } & & \multicolumn{2}{c}{ Logt-IP } \\
\cline { 2 - 3 } \cline { 5 - 6 } Model & $F$ & $P$ & & $F$ & $P$ \\
& 3.73 & 0.002 & & 3.26 & 0.004 \\
& $t$ & $P$ & & $t$ & $P$ \\
\hline Parity & -0.94 & 0.35 & & -0.52 & 0.60 \\
Age (years) & 0.43 & 0.67 & & -0.37 & 0.71 \\
Lactation indext & -2.51 & 0.02 & & -1.70 & 0.09 \\
Body fat (\%) & 3.05 & 0.004 & & 2.87 & 0.006 \\
Waist circumference (cm) & -0.59 & 0.56 & & -0.54 & 0.59 \\
SSS:ISS & 1.21 & 0.23 & & 1.38 & 0.17 \\
BMI (kg/m ${ }^{2}$ ) & -0.41 & 0.68 & & 0.34 & 0.73 \\
Oral contraceptive use & 1.42 & 0.16 & & 1.61 & 0.11 \\
$R^{2}$ & \multicolumn{2}{c}{0.35} & & \multicolumn{2}{c}{0.32} \\
\hline
\end{tabular}

SSS, superior skinfold thickness sum; ISS, inferior skinfold thickness sum * For details of subjects and procedures, see Table 1 and pp. 906-907. †Insulin response explanatory variables during the $75 \mathrm{~g}$ oral glucose tolerance test.

concentrations did not show any difference according to PBF (IAUCG $P=0 \cdot 17$ ). However, individuals with high lactation indexes need less insulin than subjects with low lactation indexes (Fig. 1).

In addition, the groups were divided according to PBF $(<25$ and $\geq 25)$ and BMI $\left(<25\right.$ and $\left.\geq 25 \mathrm{~kg} / \mathrm{m}^{2}\right)$ as follows: normal weight and normal PBF (NW-NPBF); normal weight and high PBF (NW-HPBF); high weight and high PBF (HW-HPBF). No women had high weight
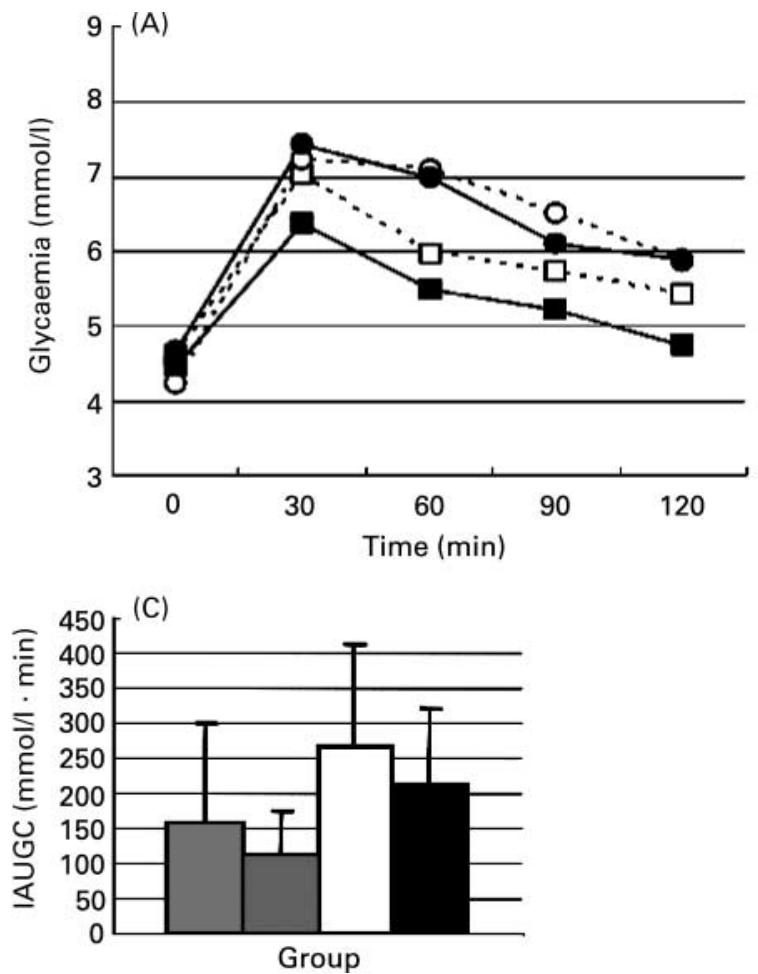

and low PBF. Table 3 presents data on these three groups. Note that the percentage of subjects classified as NW-HPBF is relatively high ( $43 \%$ of study group). The most significant result presented in Table 3 is that although NW-HPBF women did not differ in glucose load (IAUGC), they had similar insulin responses (IAUIC) to those of the HW-HPBF group. This indicates that they possessed initial insulin resistance. According to the World Health Organization (1997), NW-HPBF women have normal anthropometric values such as BMI, waist circumference and waist:hip ratio.

\section{Discussion}

For the first time, a long-term (12-18 months) protective effect of breast-feeding has been shown to be associated with variables of insulin secretion in response to a glucose load. In the literature, few studies have shown any indication that breast-feeding contributes to women's glucose metabolic status. Tigas et al. (2002) evaluated the kinetic regulation of glucose in women. Fed and fasted states in normal lactating women who were between 6 weeks and 3 months postpartum were compared with a control group of non-lactating, age-matched women. Insulin concentration, which is a known marker for increased insulin sensitivity, was lower in lactating women compared with control subjects (Duncan et al. 2001). During lactation, the rate of glucose production to meet the high demands of the mammary gland was met by increased glycogenolysis. McManus et al. (2001) evaluated the $\beta$-cell function of lactating and
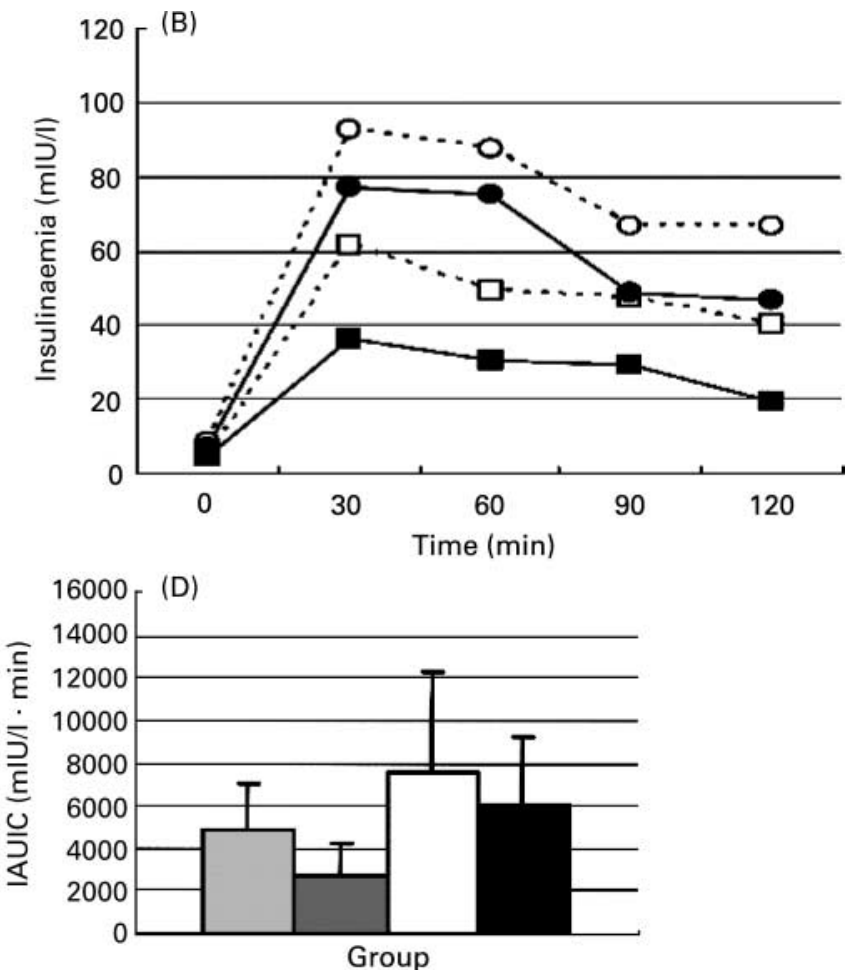

Fig. 1. Glucose and insulin curves with their respective increased areas under the curve during a $75 \mathrm{~g}$ oral glucose tolerance test. IAUGC, increased area under the glucose curve; IAUIC, increased area under the insulin curve. (A), (B): - - - $\square---$, low percentage body fat (LPBF)low lactation index (LLI) (n 5); - - - LPBF-high lactation index (HLI) (n 13); - - - O- - -, high percentage body fat (HPBF)-LLI ( $n$ 22); - HPBF-HLI ( $n$ 27). (C), (D): $\square$, low percentage body fat (LPBF)-LLI ( $n$ 5); $\mathbf{\square}$, LPBF-HLI ( $n$ 13); $\square$, HPBF-LLI ( $n$ 22); $\mathbf{\square}$, HPBF-HLI ( $n$ 27). Values are means with standard deviations shown by vertical bars. For details of subjects and procedures, see Table 1 and pp. $906-907$. 
Table 3. Demographic data, clinical data, lactation indices, anthropometric characteristics and metabolic profiles of groups classified according to percentage body fat and $\mathrm{BMI}^{*}$

\begin{tabular}{|c|c|c|c|c|c|c|}
\hline \multirow[b]{2}{*}{ Variables } & \multicolumn{2}{|c|}{ NW-NPBF ( $n$ 18; $27 \%) \dagger$} & \multicolumn{2}{|c|}{ NW-HPBF ( $n$ 29; $43 \%) \ddagger$} & \multicolumn{2}{|c|}{ HW-HPBF ( $n 20 ; 30 \%) \S$} \\
\hline & Mean & $\mathrm{Cl}$ & Mean & $\mathrm{Cl}$ & Mean & $\mathrm{Cl}$ \\
\hline Age (years) & $25 \cdot 4$ & $22 \cdot 2,28 \cdot 7$ & $28 \cdot 7$ & $26 \cdot 0,31 \cdot 3$ & $29 \cdot 7$ & $26 \cdot 1,33 \cdot 2$ \\
\hline Lactation index & $56 \cdot 1$ & $36 \cdot 8,73 \cdot 4$ & $50 \cdot 5$ & $37 \cdot 8,63 \cdot 3$ & $47 \cdot 5$ & $31 \cdot 0,63 \cdot 9$ \\
\hline Systolic pressure (mmHg) & 103.5 & $97 \cdot 4,109.6$ & $108 \cdot 1$ & $102 \cdot 5,113 \cdot 7$ & 111.5 & $105.5,117.5$ \\
\hline Diastolic pressure (mmHg) & 68.5 & $63 \cdot 3,73 \cdot 8$ & 73.4 & $70 \cdot 4,77 \cdot 2$ & $76 \cdot 9$ & $71 \cdot 0,82 \cdot 8$ \\
\hline BMI $\left(\mathrm{kg} / \mathrm{m}^{2}\right)$ & $19 \cdot 8$ & $18 \cdot 4,21 \cdot 2$ & $22 \cdot 6$ & $21 \cdot 6,23 \cdot 5$ & $28 \cdot 1$ & $26 \cdot 8,29 \cdot 5$ \\
\hline Waist circumference (cm) & $68 \cdot 6$ & $64.9,72.4$ & $75 \cdot 2$ & $73 \cdot 1,77 \cdot 4$ & $86 \cdot 7$ & $82.5,90.9$ \\
\hline Waist:hip ratio & 0.77 & $0.74,0.80$ & 0.79 & $0.77,0.81$ & 0.84 & $0.79,0.89$ \\
\hline SSS:ISS & 0.84 & $0.68,0.99$ & 0.91 & $0.82,1.00$ & $1 \cdot 01$ & $0.89,1.13$ \\
\hline Glycaemia at $t_{0}(\mathrm{mmol} / \mathrm{l})$ & 4.51 & $4 \cdot 14,4 \cdot 89$ & 4.43 & $4 \cdot 13,4 \cdot 74$ & $4 \cdot 60$ & $4 \cdot 28,4 \cdot 82$ \\
\hline Glycaemia at $t_{120}(\mathrm{mmol} / \mathrm{l})$ & 4.94 & $4 \cdot 18,5 \cdot 69$ & 5.52 & $4 \cdot 90,6 \cdot 14$ & 6.40 & $5 \cdot 26,7 \cdot 51$ \\
\hline IAUGC $(\mathrm{mmol} / \mathrm{I} \cdot \mathrm{min})$ & $126 \cdot 5$ & $66 \cdot 1,186 \cdot 8$ & $216 \cdot 5$ & $153 \cdot 3,279 \cdot 7$ & $267 \cdot 1$ & $182 \cdot 6,351 \cdot 7$ \\
\hline Insulinaemia at $t_{0}(\mathrm{mIU} / \mathrm{l})$ & 4.5 & $2 \cdot 3,6 \cdot 8$ & 6.0 & $4 \cdot 2,7 \cdot 7$ & 10.2 & $3.9,16.5$ \\
\hline Insulinaemia at $t_{120}(\mathrm{mIU} / \mathrm{l})$ & $25 \cdot 4$ & $15 \cdot 8,34.9$ & $43 \cdot 6$ & $28 \cdot 2,58 \cdot 1$ & $74 \cdot 0$ & $20 \cdot 0,127 \cdot 7$ \\
\hline HOMA index & $16 \cdot 3$ & $7 \cdot 9,24 \cdot 8$ & $21 \cdot 0$ & $14 \cdot 8,27 \cdot 3$ & $37 \cdot 1$ & $12 \cdot 8,61 \cdot 4$ \\
\hline Triacylglycerol (mmol/l) & 0.78 & $0.23,1.33$ & 0.89 & $0.67,1.10$ & 1.08 & $0.78,1.39$ \\
\hline Total cholesterol (mmol/l) & 3.59 & $2 \cdot 89,4 \cdot 30$ & $3 \cdot 84$ & $3 \cdot 42,4 \cdot 26$ & $4 \cdot 31$ & $3 \cdot 79,4 \cdot 82$ \\
\hline HDL-cholesterol (mmol/l') & $1 \cdot 14$ & $0.89,1.38$ & 0.95 & $0.78,1 \cdot 11$ & 0.92 & $0.72,1.12$ \\
\hline LDL-cholesterol (mmol/l) & $2 \cdot 30$ & $1.62,2.99$ & $2 \cdot 62$ & $2 \cdot 22,3.01$ & $3 \cdot 17$ & $2.66,3.69$ \\
\hline VLDL-cholesterol (mmol/l) & 0.16 & $0.05,0.27$ & 0.18 & $0.13,0.22$ & 0.22 & $0.16,0.28$ \\
\hline
\end{tabular}

NW, normal weight; NPBF, normal percentage body fat; HPBF, high percentage body fat; HW, high weight; SSS, superior skinfold thickness sum; ISS, inferior skinfold thickness sum; IAUGC, increased area under the glucose curve; IP, insulin peak; IAUIC, increased area under the insulin curve; HOMA, homeostasis model assessment.

* For details of subjects and procedures, see Table 1 and pp. 906-907.

†BMI $<25 \mathrm{~kg} / \mathrm{m}^{2}$ and body fat $<25 \%$.

$\ddagger$ BMI $<25 \mathrm{~kg} / \mathrm{m}^{2}$ and body fat $\geq 25 \%$.

$\S B M I \geq 25 \mathrm{~kg} / \mathrm{m}^{2}$ and body fat $\geq 25 \%$.

non-lactating women who had been diagnosed with gestational diabetes mellitus during pregnancy. Lactating women had a significantly higher glucose disposition index (insulin sensitivity $\times$ acute insulin response to glucose) compared with non-lactating women. The authors suggested that improved pancreatic $\beta$-cell function can occur while breast-feeding. We evaluated HOMA as a measure of insulin sensitivity and there was no indication of any significant change in our multiple regression model. The lack of association of HOMA with lactation index may reflect the limitations of HOMA in detecting changes in peripheral insulin sensitivity (Kirwan et al. 2001). In this way, HOMA does not accurately reflect breast-feeding-induced changes in insulin sensitivity. Similar situations have been described in athletes (Duncan et al. 2001).

Adaptations in glucose metabolism during the reproductive cycle in women have been described. Multiparity has been shown not to be associated with glucose and insulin indexes. However, controls for lactation and its effects were not included (Alderman et al. 1993). Catalano et al. (1998) evaluated changes in maternal fat mass and basal $\mathrm{O}_{2}$ consumption. They were inversely related to changes in insulin sensitivity. Catalano et al. (1998) hypothesized that decreased insulin sensitivity before parturition in lean women is an advantage to survival, since this results in large amounts of available substrate that could be used to meet feto-placental needs during gestation. Insulin resistance as it relates to glucose metabolism results in decreased glucose uptake in peripheral tissues and an inability to suppress endogenous glucose production and lipolysis. The idea that development of insulin resistance during late pregnancy is a physiological adaptation to special mother-fetus requirements was stressed by Sivan et al. (1999) and Butte et al. (1999). In the third semester of gestation, Sivan et al. (1999) showed a decreased inhibition of lipolysis during euglycaemic-hyperinsulinaemic clamping, although fat oxidation remained uninhibited. This physiological adaptation may result in net tissue accretion. It has been demonstrated in experimental animals after parturition that there is a change from a state of overall insulin resistance to insulin sensitivity. Low insulin levels lead to a state of fat mobilization and a redirection of substrates to the mammary gland (Williamson, 1980; Marynissen et al. 1983; Madon et al. 1990). Zhong et al. (1990) observed that overall insulin response to an intravenous glucose tolerance test in lactating rats was greater than in non-lactating rats, despite a prolonged (three pregnancy-lactation cycles) body weight and adiposity retention in lactating animals. The results obtained by Zhong et al. (1990) are in agreement with our observation of a protective long-term effect of lactation on insulin response. In women 6 months postpartum, Butte et al. (1999) verified that there was a higher mean $24 \mathrm{~h}$ respiratory quotient and higher rate of carbohydrate utilization in the lactation group than in the non-lactation group. The lactating women studied by Butte et al. (1999) had lower levels of insulin compared with a non-lactating group at 3 and 6 months postpartum. These results are consistent with the idea of preferential use of glucose by the mammary gland. In fact, insulin has well known roles in 
mammary gland function: it stimulates glucose and lipogenesis (Williamson, 1990; Neubauer et al. 1993) and controls mammary gland lipoprotein lipase (Neville et al. 1991; Da Costa \& Williamson, 1994; Ramos et al. 1999).

Another significant finding in the present study is that $\mathrm{PBF}$ is an independent predictor of insulin response in the $75 \mathrm{~g}$ oral GTT during the postnatal period (Table 2). The results presented in Table 3 show that that if PBF is high, low BMI, waist:hip ratio and/or waist circumference do not necessarily lead to a low incidence of metabolic alterations, as evidenced by the higher levels of insulin throughout the oral GTT. These results concur with those of Cnop et al. (2002), who found a positive relationship between intra-abdominal fat and insulin resistance among lean (normal BMI and waist:hip ratio) as well as obese women with an insulin-resistant state. Dvorak et al. (1999) found that $18 \%$ of the women with normal BMI values had obese metabolic profiles.

This present study is cross-sectional in design, but we used methodological alternatives (Dawson-Saunders \& Trapp, 1994) to avoid the influence of confounding variables. In the recruitment phase, women were matched for parity and age range. Pertinent adjustments were made during statistical analysis. Our group of parous women had similar average ages (primiparous 25.8 (95\% CI $23.7,27.8)$ years; multiparous 29.9 (95\% CI 27.5, 32.5) years) to those obtained by Coitinho et al. (2001) in which a representative sample of Brazilian women was assessed $(24.4,28.3$ and 32.0 years for women with one, two and three children respectively). The mean number of children per woman in the present study (1.76 $(95 \%$ CI 1.53, 1.99)) is lower than that in Brazil $(2.21)$ and in satellite cities of Brasilia (2.12; Instituto Brasileiro de Geografia e Estatística, 1999). This difference can be explained by the high number of primiparous women included in the present study $(45 \%)$ due to the selection methods used. In Brazil, the frequency of primiparous women is $34 \%$. We are aware that despite the methodological alternatives used, the major disadvantage of a cross-sectional study remains lack of control of temporal sequence of events. To control confounded variables and to guarantee internal validity, women were recruited with specific characteristics that may not be representative of female patients of the University of Brasilia Hospital. For these reasons, the results presented in the present study should be extrapolated with caution.

In our previous study (Rodrigues \& Da Costa, 2001), we reinforced the idea that physiological changes during pregnancy and lactation periods are associated with long-term retention of adiposity. Reproduction can be a vulnerable period for future development of obesity (Williamson et al. 1994; Harris et al. 1997; Wolfe et al. 1997). Moreover, much like the physiological, psychosocial and social changes that accompany motherhood, energy metabolism may be changed by control mechanisms involved in energy expenditure and/or food intake (Harris \& Ellison, 1997; Harris et al. 1999).

Excessive adiposity retention should be avoided to prevent metabolic abnormalities. Obese women are at great risk of precociously developing chronic diseases. Anthropometric measurements of women during their reproductive cycle should include a PBF evaluation. Food intake and selection are important factors in adiposity accretion. For this reason, nutritional counselling should occur during pregnancy and lactation periods. Moreover, lactation stimuli do not appear to be sufficient to induce an overall mobilization of body adiposity in urban women. Nevertheless, as indicated by the present study, independent of body adiposity, lactation can act as a long-term protector that improves hormonal control of insulin-glucose homeostasis. Lactation results in a more sensitive insulin state. This could be adventitious as protection against type 2 diabetes, hyperlipidaemia and hypertension. Further research is needed to explain the mechanisms involved in the association between breast-feeding and insulin sensitivity.

\section{Acknowledgements}

We thank all volunteers who participated in this study. We also express our gratitude to Dr Édina S. Miazaki for performing the statistical analysis; Dr Nadia Trugo for help with insulin determination; Ms Adriana B. Rayol and Ms Paula N. R. Mendes for help in data collection; Mr Werte S. Chaves for technical assistance in blood collection; the staff at the Paediatric Clinic of the University of Brasilia Hospital, and Professor J. G. Dorea for helpful discussion of the manuscript. This work received financial support from the Fundação de Apoio à Pesquisa do Distrito Federal (FAP-DF; grant no. 193378/95-0767) and CNPq (Conselho Nacional de Desenvolvimento Científico e Tecnológico), and a master's scholarship for J.M.M.D. and two undergraduate student scholarships (PIBIC).

\section{References}

Alderman BW, Marshall JA, Boyko EJ, Markham KA, Baxter J \& Hamman RF (1993) Reproductive history, glucose tolerance, and NIDDM in hispanic and non-hispanic white women. Diabetes Care 16, 1557-1564.

Butte NF, Hopkinson JM, Mehta N, Moon JK \& Smith O'B (1999) Adjustments in energy expenditure and substrate utilization during late pregnancy and lactation. Am J Clin Nutr 69, 299-307.

Butte NF, Wong WW \& Hopkinson JM (2001) Energy requirements of lactating women derived from doubly labeled water and milk energy output. $J$ Nutr 131, 53-58.

Brewer MM, Bates MR \& Vannoy LP (1989) Post-partum changes in maternal weight and body fat depots in lactating vs nonlactating women. Am J Clin Nutr 49, 259-265.

Catalano PM, Roman-Drago NM, Amini SB \& Sims EA (1998) Longitudinal changes in body composition and energy balance in lean women with normal and abnormal glucose tolerance during pregnancy. Am J Obstet Gynecol 179, 156-165.

Cnop M, Landchild MJ, Vidal J, et al. (2002) The concurrent accumulation of intra-abdominal and subcutaneous fat explains the association between insulin resistance and plasma leptin concentrations: distinct metabolic effects of two fat compartments. Diabetes 51, 1005-1015.

Coitinho DC, Sichieri R \& Benício MHD’A (2001) Obesity and weight change related to parity and breastfeeding among parous women in Brazil. Public Health Nutr 4, 865-870.

Da Costa THM \& Williamson DH (1994) Regulation of rat mammary-gland uptake of orally administered $\left[1-{ }^{14} \mathrm{C}\right]$ triolein by insulin and prolactin: evidence for bihormonal control of lipoprotein lipase activity. Biochem J 300, 257-262. 
Dawson-Saunders B \& Trapp RG (1994) Basic and Clinical Biostatistics, 2nd ed. London: Prentice Hall International.

Duncan GE, Hutson AD \& Stacpoole PW (2001) Quicki does not accurately reflect changes in insulin sensitivity with exercise training. J Clin Endocrinol Metab 86, 4115-4119.

Durnin JVGA \& Womersley J (1974) Body fat assessed from total body density and its estimation from skinfold thickness. Measurements on 481 men and women aged from 16 to 72 years. Br J Nut 32, 77-97.

Dvorak RV, Denino WF, Ades PA \& Poehlman ET (1999) Phenotypic characteristics associated with insulin resistance in metabolically obese but normal-weight young women. Diabetes 48, 2210-2214.

Friedewald WT, Levy RI \& Fredrickson DS (1972) Estimation of the concentration of low-density lipoprotein cholesterol in plasma, without use of the preparative ultracentrifuge. Clin Chem 18, 499-502.

Goldberg GR, Black AE, Jebb SA, Cole TJ, Murgatroyd PR, Coward WA \& Prentice AM (1991) Critical evaluation of energy intake data using fundamental principles of energy physiology. 1. Derivation of cut-off limits to identify underrecording. Eur J Clin Nutr 45, 569-581.

Harris HE \& Ellison GTH (1997) Do the changes in energy balance that occur during pregnancy predispose parous women to obesity? Nutr Res Rev 10, 57-81.

Harris HE, Ellison GTH \& Cement S (1999) Do the psychosocial and behavioral changes that accompany motherhood influence the impact of pregnancy on long-term weight gain? J Obstet Gynecol 20, 65-79.

Harris HE, Ellison GTH \& Holliday M (1997) Is there an independent association between parity and maternal weight gain? Ann Hum Biol 24, 507-519.

Instituto Brasileiro de Geografia e Estatística (1999). www. ibge.net/home/estatística/população/trabalhoerendimento/ pnad99/sintese/tabela.shtm

Khan LK \& Bowman BA (1999) Obesity: a major global public health problem. Ann Rev Nutr 19, xiii-xvii.

Kirwan JP, Huston-Presley L, Kalhan SC \& Catalano PM (2001) Clinically useful estimates of insulin sensitivity during pregnancy. Diabetes Care 24, 1602-1607.

McManus RM, Cunningham I, Watson A, Harker I \& Finegood DT (2001) Beta-cell function and visceral fat in lactating women with a history of gestational diabetes. Metabolism 50, 715-719.

Madon RJ, Ensor DM \& Flint DJ (1990) Hypoinsulinaemia in the lactating rat is caused by a decreased glycaemic stimulus to the pancreas. $J$ Endocrinol 125, 81-88.

Marynissen G, Aerts L \& Van Assche FA (1983) The endocrine pancreas during pregnancy and lactation in the rat. J Dev Physiol 5, 373-381.

Matthews DR, Hosker JP, Rudenski AS, Naylor BA, Treacher DF \& Turner RC (1985) Homeostasis model assessment: insulin resistance and $\beta$-cell function from fasting plasma glucose and insulin concentrations in man. Diabetologia $\mathbf{2 8}$, 412-419.

Matthews JNS, Altman DG, Campbell MJ \& Royston P (1990) Analysis of serial measurements in medical research. $\mathrm{Br}$ Med $J$ 300, 230-235.

Monteiro CA, Benício MHD'A, Conde WL \& Popkin BM (2000) Shifting obesity trends in Brazil. Eur J Clin Nutr 54, 342-346.

Monteiro CA, Mondini L, Souza ALM \& Popkin BM (1995) The nutrition transition in Brazil. Eur J Clin Nutr 49, 105-113.

Ness RB (1995) Parity, adiposity and body fat distribution among Hispanic women. Am J Hum Biol 7, 657-663.

Neubauer SH, Ferris AM, Chase GG, Fanelli J, Thompson CA, Lammi-Keefe CJ, Clark RM, Jensen RG, Bendel RB \& Green KW (1993) Delayed lactogenesis in women with insulin-dependent diabetes mellitus. Am J Clin Nutr 58, 54-60.
Neville MC, Waxman LJ, Jensen D \& Eckel RH (1991) Lipoprotein lipase in human milk: compartmentalization and effect of fasting, insulin, and glucose. J Lipid Res 32, 251-257.

Piers LS, Diggavi SN, Thangam S, van Raaij JM, Shetty PS \& Hautvast JG (1993) Changes in energy expenditure, anthropometry, and energy intake during the course of pregnancy and lactation in well-nourished Indian Women. Am J Clin Nutr 57, 497-505.

Ramos P, Martín-Hidalgo A \& Herrera E (1999) Insulin-induced up-regulation of lipoprotein lipase messenger ribonucleic acid and activity in mammary gland. Endocrinology 140, 1089-1093.

Rodrigues ML \& Da Costa THM (2001) Association of the maternal experience and changes in adiposity measured by BMI, waist:hip ratio and percentage body fat in urban Brazilian women. Br J Nutr 85, 107-114.

Siri WE (1961) Body composition from fluid spaces and density: analysis of methods. In Techniques for Measuring Body Composition, pp. 223-224 [J Brozek and A Henschel, editors]. Washington: National Academy of Science.

Sivan E, Homko CJ, Chen X, Reece EA \& Boden G (1999) Effect of insulin on fat metabolism during and after normal pregnancy. Diabetes 48, 834-838.

Smith DE, Lewis CE, Caveny JL, Perkins LL, Burke GL \& Bild DE (1994) Longitudinal changes in adiposity associated with pregnancy. The CARDIA Study. Coronary Artery Risk Development in Young Adults Study. J Am Med Assoc 271, $1747-1751$.

Soltani H \& Fraser RBA (2000) Longitudinal study of maternal anthropometric changes in normal weight, overweight and obese women during pregnancy and post-partum. $\mathrm{Br} J \mathrm{Nutr}$ 84, 95-101.

The Institute of Medicine (1990) Nutrition during Pregnancy. Part 1: Weight gain. Subcommittee on Nutrition Status and Weight Gain during Pregnancy. Subcommittee as Dietary Intake and Nutrient Supplements during Pregnancy. Committee on Nutritional Status during Pregnancy and Lactation. Food and Nutrition Board. National Academy of Sciences. Washington D.C.: NAP

Tigas S, Sunehag A \& Haymond MW (2002) Metabolic adaptation to feeding and fasting during lactation in humans. $J$ Clin Endocrinol Metab 87, 302-307.

Williamson DF, Madans J, Pamuk E, Flegal KM, Kendrick JS \& Serdula MK (1994) A prospective study of childbearing and 10-year weight gain in US white women 25 to 45 years of age. Int J Obes Relat Metab Disord 18, 561-569.

Williamson DH (1980) Integration of metabolism in tissues of the lactating rat. FEBS Lett 117, Suppl., K93-K105.

Williamson DH (1990) The lactating mammary gland of the rat and the starved-refed transition: a model system for the study of the temporal regulation of substrate utilization. Biochem Soc Trans 18, 853-856.

Wolfe WS, Sobal J, Olson CM \& Frongillo EA Jr (1997) Parityassociated body weight: modification by socio-demographic and behavioral factors. Obes Res 5, 131-141.

World Health Organization (1997) Obesity: Preventing and Managing the Global Epidemic. Report of a WHO Consultation on Obesity. Geneva: WHO.

World Health Organization (1999) Definition, Diagnosis and Classification of Diabetes Mellitus and its Complications. Report of a WHO Consultation. Part 1: Diagnosis and Classification of Diabetes Mellitus. Geneva: WHO.

Zhong S, Almario R, Dubrinsky M, Rose K, Lin PKH, Grunberger G \& Jen K-LC (1990) Repeated pregnancy without lactation: effects on maternal glycemic control, pregnancy outcome, carcass composition, and fat distribution in rats. Metabolism 39, 1127-1132. 